\title{
ENDOCARDIAL FIBROSIS
}

\author{
BY \\ IAN R. GRAY \\ From University College Hospital \\ Received May 5, 1951
}

Fibrosis of the myocardium and endocardium causing chronic cardiac failure is most frequently seen with disease of the coronary arteries. Occasional cases occur, however, where the blood vessels are normal and among these a group may be recognized in which fibrosis is confined to the endocardium and to the myocardium immediately underlying it. The pathological and clinical features of this condition are to be described and two further cases reported.

The endocardium is thickened and opaque and there is often mural thrombosis. Fibrous tissue extends into the myocardium along the thebesian veins, and there is necrosis and replacement fibrosis confined to the adjacent muscle. Inflammatory changes are not found and endocardial fibrosis seems a suitable descriptive term.

Most cases occur in young adults but it has been described in children, and some cases are recorded as idiopathic hypertrophy of the heart (Kugel and Stoloff, 1933; Mahon, 1936). The onset is insidious with congestive cardiac failure. There is often a slight fever. The heart is enlarged, but the cardiac impulse is weak and the blood pressure low. Systolic murmurs and occasionally thrills have been described. Sooner or later gallop rhythm appears and frequently alternation of the pulse. Emboli from mural thrombus may obstruct small or large arteries. The electrocardiogram is abnormal, usually showing low voltage curves, and flat or inverted $\mathrm{T}$ waves in one or more leads. The rhythm is usually regular but disorders of rhythm and conduction occasionally occur. If mural thrombosis does not occur the disease may last for several years. Improvement often occurs with rest and treatment but a fatal outcome is inevitable. If massive intra-cardiac thrombosis takes place, the effective ventricular cavity becomes greatly decreased and death occurs from rapidly developing cardiac failure or multiple emboli.

The earliest account of the condition is that of Josserand and Gallavardin in 1901 who described it as primary subacute myocarditis and recorded three cases. In 1914 a further case in which progressive cardiac failure was accompanied by multiple embolic accidents was reported by Roque and Levy and yet another by Gallavardin and Gravier in 1929. A single case was fully described from the pathological standpoint by Boikan (1931) as myocarditis perniciosa and he contrasted the findings with those in the recognized forms of myocarditis. In 1936 Loeffler described a syndrome of endocarditis parietalis fibroplastica with eosinophilia and reported two cases which conform closely with the condition under discussion, and further examples of this were recorded by Mumme (1940) and Egger (1944). The earliest cases in America were reported by Levy and Rousselot (1933) as cardiac hypertrophy of unknown aetiology in young adults. Three cases with great cardiac enlargement, endocardial fibrosis and multiple emboli from mural thrombosis were described. Three out of five cases of cardiac failure of unknown cause recorded by Reisinger and Blumenthal (1941) appear to be examples of endocardial fibrosis, and three cases were described in detail by Smith and Furth (1943) as fibrosis of endocardium and myocardium with mural thrombosis. Further reports appeared under the titles of diffuse isolated myocarditis (Toreson, 
1944) and chronic fibroplastic myocarditis (Ware and Chapman, 1947) and a pathological study of two cases of Flynn and Mann (1946) drew attention to the effects of endocardial fibrosis on the blood supply of the adjacent myocardium.

The condition was always considered uncommon until 1946 when Bedford and Konstam briefly described forty cases encountered in the Middle East in West African soldiers. Necropsy confirmed the diagnosis of endocardial fibrosis in seventeen of them. In 1948 Davies described the pathological findings in fifty-two cases in East Africa where it is the cause of 10 per cent of all cases of cardiac failure, and Edge (1946) described a case in a European soldier who fell ill while stationed in West Africa.

The prevalence of this disease in Africa may shed light on its cause, and its recognition in Europeans spending a relatively short period there may also be significant. Two further cases of endocardial fibrosis in Europeans living in West Africa are to be described.

Case 1. A 40-year-old doctor who had served in Nigeria in the Colonial Medical Service for 9 years. He had jaundice in 1936 following yellow-fever immunization, and one attack of malignant tertian malaria, and early in 1944 had swellings of the arms attributed to loa-loa. He began to feel unwell in August, 1944, and was found to have an eosinophilia of 35 per cent. In January, 1945, he first had attacks of dyspnœa and cough relieved by injections of neoarsphenamine. An enlarged axillary gland was removed which showed lymphoid hyperplasia with eosinophylic infiltration. In April, 1945, he noticed low fever, aching in the limbs and chest, and increasing dyspnœa on effort. He returned to England in June and on July 3, 1945, was admitted to St. Thomas' Hospital.

On admission: T. 99.0; P. 100 (regular); R. 25; B.P. 115/95. Examination,showed a well-nourished man who was dyspnœic and had signs of congestive cardiac failure. The heart was enlarged five inches to the left and a soft systolic murmur and a protodiastolic gallop were heard at the apex. There was marked congestion of the jugular veins with free systolic pulsation, and there was a pleural effusion on the right, and a large tender liver. The leucocyte count was $21,800 / \mathrm{cu}$. $\mathrm{mm}$. with 51 per cent eosinophils. Fig. 1 shows right axis deviation, slightly depressed S-T segments in leads II and III and low T waves. Circulation time from arm to tongue $(5 \mathrm{ml}$. decholin) was 22 seconds. Injections of neoarsphenamine g. 0.45 afforded no relief. He was digitalized but without effect on the cardiac failure and on August 22, because the size of the heart was increasing, pericardial aspiration was attempted, but a small amount of fresh blood only was withdrawn. His condition was deteriorating, but very slowly, and the blood pressure fell to $95 / 80$ with pulsus alternans. He was given injections of neptal with good results and was discharged in October, 1945. He remained in chronic congestive failure for the next year and died in November, 1946.

Necropsy. The body of a well-nourished man with cyanosis of the extremities and œdema of the legs.

Respiratory system: $300 \mathrm{ml}$. of yellowish fluid were in each pleural cavity. There were fairly dense adhesions over both lungs and between pleura and pericardium. The lungs were odematous and showed patchy collapse. The pulmonary arteries were dilated and prominent and were flecked with atheroma.

Heart. There was a slight excess of clear fluid in the pericardium and numerous petechial hæmorrhages over the heart. The right auricle and ventricle and the left auricle were greatly dilated, and the left ventricle slightly so. Endocardial fibrosis at apex of the hypertrophied right ventricle extended into the papillary muscles. Organizing fibrous tissue caused adherence of the septal end of the tricuspid valve to the ventricular wall. The lower two-thirds of the left ventricular cavity were lined with fibrous tissue. The marginal cusp of the mitral valve was slightly adherent to the ventricular wall. There was moderate atheroma of the right and slight atheroma of the left coronary arteries. Other vessels were healthy.

Abdomen. Several pints of brownish ascitic fluid were present. There was severe chronic heart failure change in the liver with some fibrosis. Spleen was enlarged and congested and there was cedema and fibrosis of the pancreas. A recent infarct was present in the left kidney, and a calcified tuberculous gland was found at the ileocæcal junction.

Microscopy. Heart. Normal pericardium, with healthy coronary vessels. There is a mild diffuse interstitial fibrosis of the myocardium with patchy scarring which is confined almast entirely to the papillary muscles and to the myocardium immediately below the endocardium. The thebesian veins are dilated and contain loose connective tissue in which numerous thin-walled vessels and some iron-containing pigment are found. The endocardium is greatly thickened by old dense hyaline fibrous tissue and some areas of 
loose connective tissue which like the thebesian veins contain thin-walled blood vessels and iron pigment. There are only a few peri-vascular leucocytes in the endocardium and no evidence of any active necrosis or inflammation. The endocardial fibrous tissue is covered by an intact endothelium and there is no mural thrombus (see Fig. 2).

Liver, passive venous congestion with early cardiac cirrhosis. Kidneys, small white infarct with arterial thrombus. Lung, congested; alveoli contain heart failure cells; small branches of pulmonary arteries contain ante-mortem thrombi. Spleen, voluntary muscle, intestine, and pituitary show no significant changes.
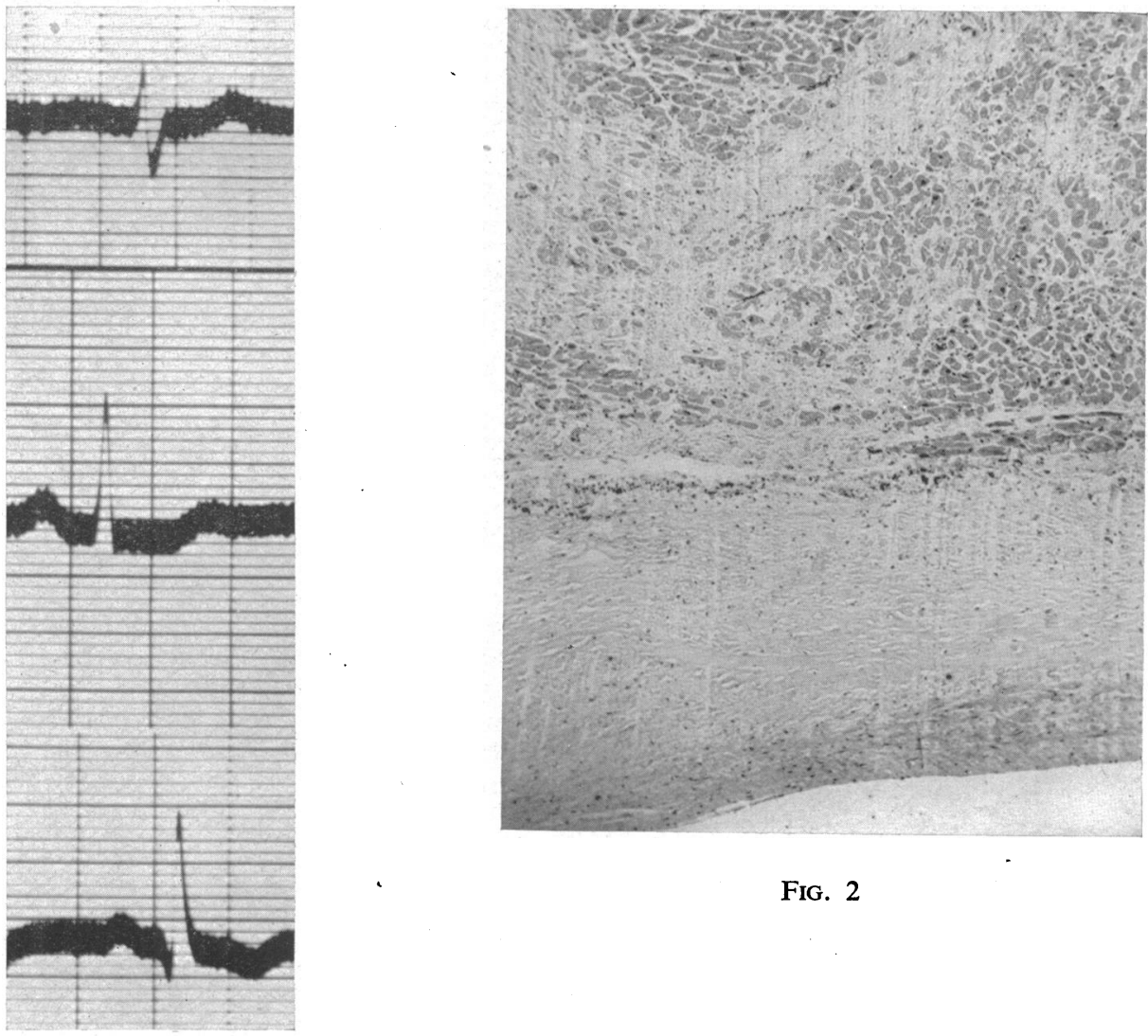

FIG. 2

FIG. 1

Fig. 1.-Case 1. Sinus rhythm. Right axis deviation. T wave inverted in lead III. S-T segment slightly depressed in lead II.

FIG. 2.-Case 1. Low-power view of endocardium and underlying myocardium of left ventricle. Endothelium is intact. There is fibrous thickening of endocardium. There is considerable postnecrotic scarring of the underlying muscle.

Case 2. A district magistrate, aged 36, who had lived in Nigeria since 1946. There was no history of serious illness and his health while in Africa was excellent except for some lumps on the arms which appeared for a few days during summer, 1949, attributed to loa-loa. He first felt unwell in December, 1949, with fatigue, low fever and sweating, symptoms which were unaffected by anti-malarial therapy. He sailed for England in January, 1950, and on arrival still felt out of sorts. He was seen by a doctor on January 29, when he had a normal temperature and a pulse rate of 120; heart sounds were distant and rhonchi were heard throughout the chest. He was admitted to hospital and examination revealed an enlarged liver, and an exudate and several hæmorrhages in the left fundus. He complained of severe headache and 
developed exaggerated reflexes with extensor plantar responses and bilateral ankle clonus. Blood smears were repeatedly negative for malarial parasites and lumbar puncture showed a high pressure (over $300 \mathrm{~mm}$. water) and slightly raised protein $(45 \mathrm{mg}$. per $100 \mathrm{ml}$.) in the spinal fluid. No trypanosomes were seen in the spinal fluid or in fluid aspirated from an enlarged cervical gland. The temperature rose to $102^{\circ} \mathrm{F}$. and he became drowsy, irrational and incontinent. He was transferred on February 16, to the Hospital for Nervous Diseases, Queen Square, with an established spastic tetraplegia. The fundi were normal, heart sounds were distant and congestive failure was present. There was a leucocytosis $(13,100 / \mathrm{cu} . \mathrm{mm}$.) with an eosinophilia of 18 per cent. On February 23, the Wassermann and Kahn reactions were positive. Neurological signs gradually diminished and the mental state improved but congestive failure increased. He was transferred to University College Hospital on March 29.

On examination: T. $99 \cdot 4^{\circ}$; P. 120 (regular); R. 28; B.P. 110/80. Cyanosed with sluggiśh peripheral circulation, and venous congestion up to the ears with very free systolic pulsation. Congestive cardiac failure with considerable odema, ascites, and pleural effusions. Heart enlarged, left border $15 \mathrm{~cm}$. to left in 5th space and right border $4 \mathrm{~cm}$. to the right. Apex beat could scarcely be felt. A protodiastolic gallop was heard shortly after admission and persisted thereafter. There were no murmurs. Signs of spastic tetraplegia were disappearing.

He was treated with digitalis, a low-salt diet and restricted fluids. Mercurial diuretics were exhibited as long as they were effective. Wassermann reaction was negative on March 29. Fig. 3 shows normal rhythm with right axis deviation and normal conduction, low-voltage complexes in all leads, flat T1 and T2, inverted T3 and slight depression of S-T in lead II. X-ray showed an enlarged heart with bilateral pleural effusions. E.S.R. was $16 \mathrm{~mm}$. in 1 hour.

Thiamine chloride $20 \mathrm{mg}$. was given intramuscularly daily for 32 days. Mercurial diuretics ceased to be effective after four injections. Slow improvement occurred for 4 weeks. After this his mental state began to deteriorate, venous congestion increased and the peripheral circulation became gradually more sluggish. On May 6 he collapsed and became very breathless and cyanosed. Pulmonary embolism was suspected, and he died a few hours later.

Necropsy (Dr. J. D. Judah). The well-developed body of a young man. There was pitting œdema of the legs and the abdomen was distended. Both pleural cavities contained large amounts of turbid fluid. Pleural surfaces were normal.

Lungs: R. 670 g; L. 370 g. The right lung contained several,small ante-mortem thrombi in smaller vessels. There was no actual infarction. There were no thrombi or emboli in the left lung. There was no pulmonary œdema or bronchopneumonia, and no atheroma of the pulmonary vessels.

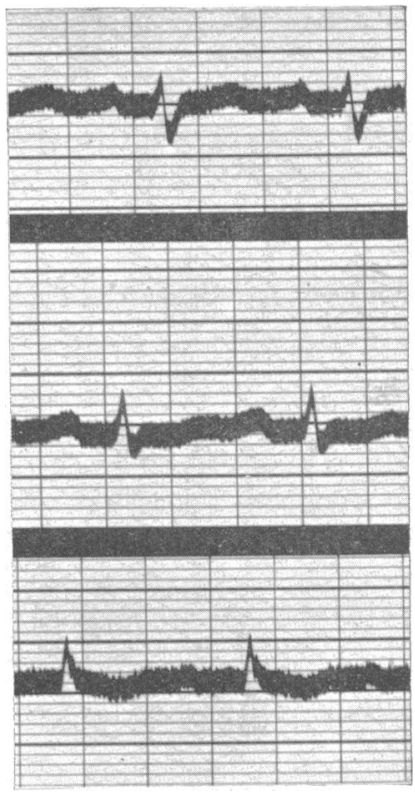

Fig. 3.-Case 2. Sinus rhythm. Low-voltage curves with right axis deviation. $T$ waves low in all leads, inverted in lead III.

Heart: $600 \mathrm{~g}$. The heart was greatly enlarged and there was some yellow turbid fluid in the pericardial sac, but no pericarditis. The cavities of both ventricles were almost filled with tough organizing thrombus firmly bound down to the endocardium (Fig. 4). In the right ventricle thrombus almost reached the tricuspid valve leaving a very small effective ventricular cavity. On the left thrombosis was rather less extensive covering only the apical and septal portions of the ventricular wall. The auricles were free of thrombus but the right auricle was enlarged and hypertrophied so that the auricular appendage was reduced to a slit. The valves were normal except for fenestration of one cusp of the aortic valve. The great vessels were normal without any sign of atheroma or syphilis. The coronary vessels and their branches were dissected out and showed no sign of atheroma or thrombosis. The cut surface of the ventricular wall showed advanced organization of the thrombus which was in places inseparable from the endocardium which was itself greatly thickened throughout the greater part of both ventricles. The inner half of the ventricular wall was whitish in colour with fibrous tissue spreading into it from the thick fibrous endocardium. Liver: $1820 \mathrm{~g}$.; enlarged with a deep red and yellow mottled appearance. It was firm in texture and the portal and hepatic vessels were normal. Kidneys: normal macroscopically. Alimentary canal: there was a leash of dilated and engorged veins at the lower end of the esophagus, but no other abnormality. There was about nine pints of ascitic fluid. Vessels: an antemortem thrombus was found 
in the right femoral vein. Other vessels were normal. Brain: the brain was somewhat œematous. The great vessels appeared normal, but there was great congestion of the veins. The gyri were somewhat flattened. Petechiad hæmorrhages were scattered throughout the brain, and there were numerous small slightly pigmented scars. On the right side, the internal capsule and caudate nucleus were involved in a large area of softening of fairly recent origin.

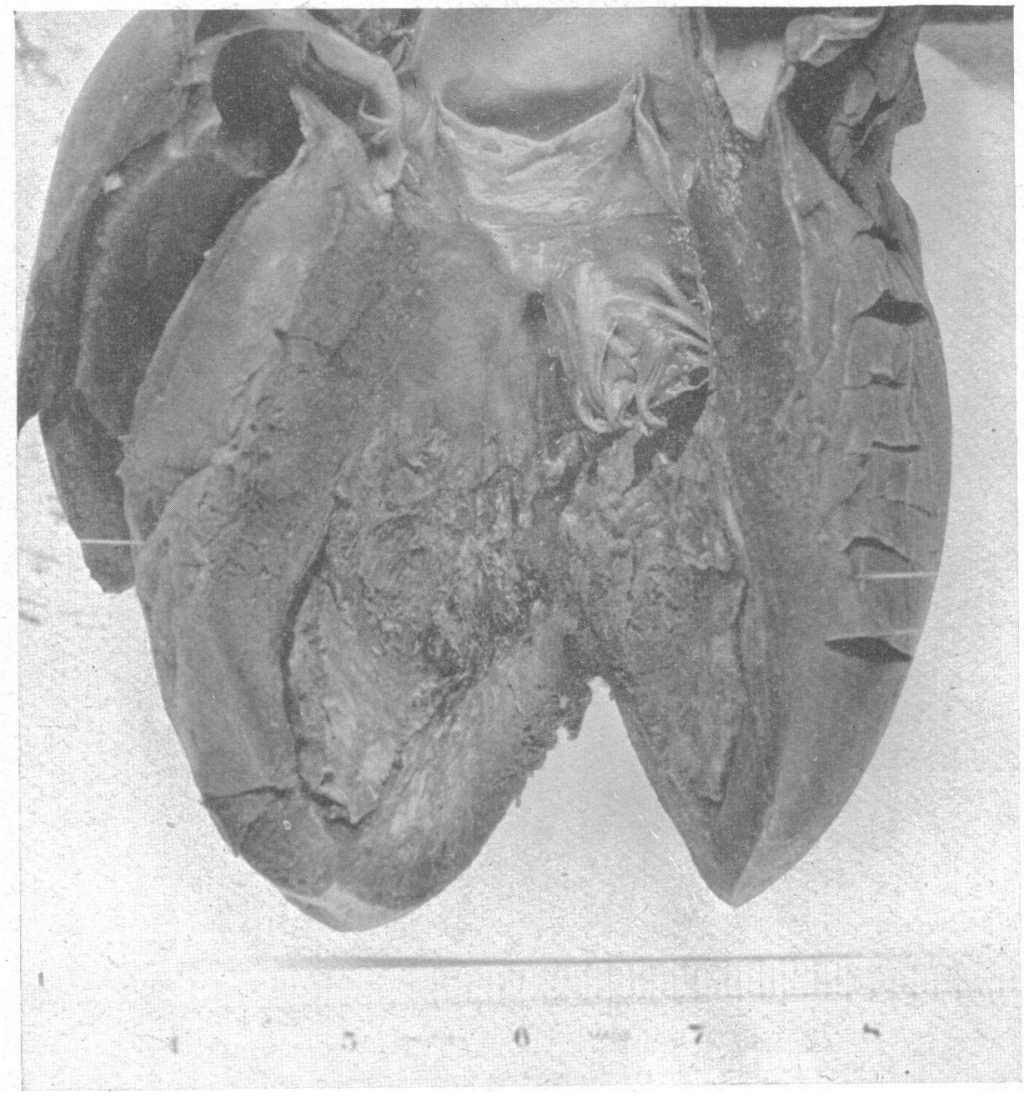

FIG. 4.-Case 2. Left ventricle opened to show extensive organizing thrombus filling the apex of the cavity.

Microscopy. Heart: pericardium normal; myocardium shows several post-necrotic fibrous scars from multiple emboli in the smaller coronary arteries and arterioles; these emboli are largely composed of platelets and fibrin and resemble the structure of the friable superficial parts of the endocardial thrombus. The intra-mural thebesian veins are distended and their lumina filled with loose connective tissue in which much iron-containing pigment and numerous capillaries are seen. Some of these capillaries are proliferating and many others show ectasia. These veins appear to have been obstructed, to have thrombosed, and to be partly recanalized, the young capillaries being stuffed with red cells suggesting that obstruction persists. The endocardium is grossly thickened, being made up of loose connective tissue in which small areas of dense collagen are found; much iron-containing pigment is present in these areas. Overlying the thickened endocardium is a deep layer of ante-mortem platelet and fibrin thrombus. Young capillaries and fibroblasts are growing into this clot (Fig. 5). Both right and left ventricles show these endocardial changes. Coronary arteries are normal apart from the emboli in their smaller branches.

Lungs: mucous bronchitis, patchy atelactasis. A few small branches of the pulmonary arteries contain blood-clot emboli. Liver: back pressure changes and early cardiac cirrhosis. Spleen and kidneys: several small emboli. Brain: arterioles of the brain contain several blood-clot emboli with small foci of cerebral 
softening in which scavenger cells are found. Voluntary muscle: normal muscle fibres. Some perivascular and perimural aggregates of lymphocytes and polymorphonuclear leucocytes but no changes specific of polyarteritis nodosa.

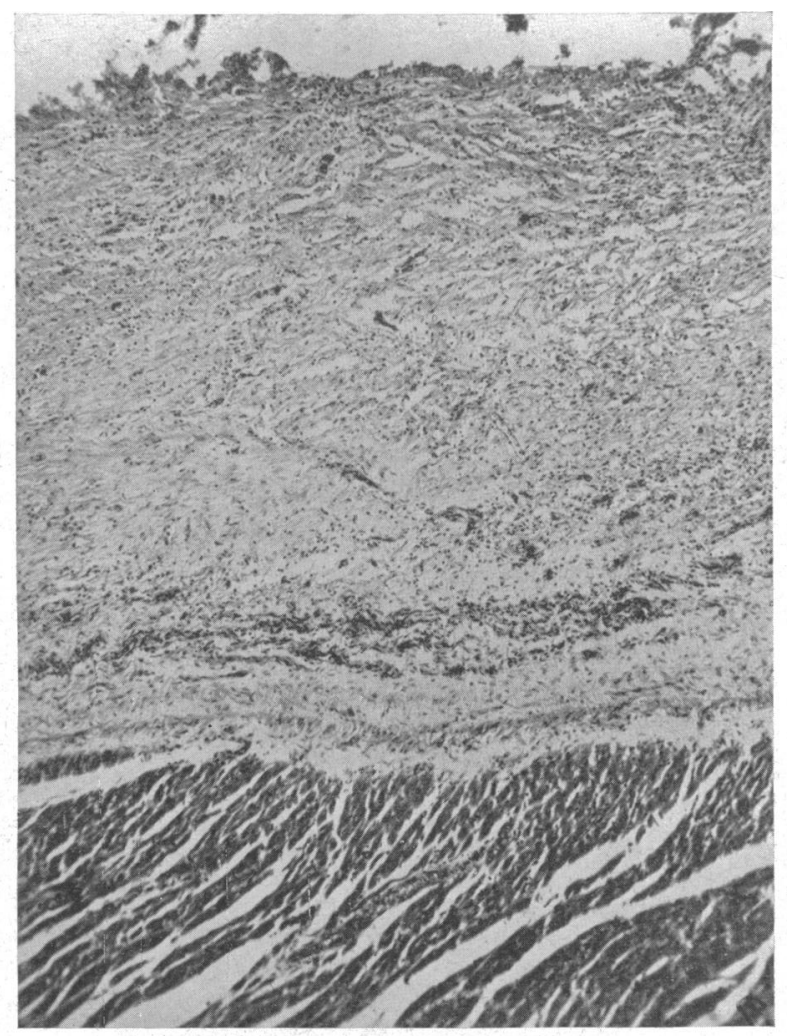

Fig. 5.-Case 2. Low-power view showing greatly thickened endocardium with loss of the endothelium. Underlying muscle is healthy.

\section{DISCUSSION}

The clinical picture of chronic congestive failure, regular pulse, low blood pressure, enlarged heart with gallop rhythm, and indefinite electrocardiographic changes could be found in any severe myocardial lesion. The absence of anginal pain is worth emphasis as it may help in distinguishing these cases clinically from coronary artery disease. The widespread small emboli found in the brain were undoubtedly the cause of the neurological findings in Case 2 and it was their multiplicity that made diagnosis difficult. Similar signs were found in the case of Edge (1946). They were attributed to the effect of arsenical therapy, but since the brain was not examined at necropsy proof of this was lacking, and the extensive mural thrombus in the left ventricle made an embolic lesion likely.

The eosinophilia could be attributed to loa-loa. It has, however, been described previously in endocardial fibrosis. Not only is it mentioned by Davies (1948) in his cases in East Africa but also in the Continental literature. The two cases of Loeffler (1936) had an eosinophilia of 70 per cent and that of Egger (1944) also had a high count. The remarkable case of Mumme (1940) may be mentioned where eosinophilia of 60 per cent was found and fibrosis of the endocardium occurred with fibroplastic inflammation of the aorta and thrombo-arteritis obliterans of the visceral 
and cerebral vessels. Although eosinophilia might be disregarded in Africa where parasitic infestations are common, in Europe it is usually significant.

The lumps noticed on the arms were 2.5 to $7.5 \mathrm{~cm}$. in diameter, itching but not painful, and lasted only a few days. Any such lesions occurring in West Africa are likely to be attributed to loa-loa. In these two cases there were no ocular symptoms and no microfilaria were found in the blood later on. It seems possible that these skin lesions had some significance in relation to the cardiac disease that developed later.

The essential lesion in both cases was an intense fibrosis of the subendothelial connective tissue of the endocardium. If this was the result of an inflammatory process no evidence of it remained. In Case 1 the endothelium was intact; the fibrosis extended into the myocardium along the thrombosed thebesian veins. There was also extensive fibrosis in the subendocardial muscle which appeared to have followed necrosis of muscle; here again there was no cellular reaction. This scarring of the subendocardial muscle seemed due to interference with its blood supply which is largely direct from the ventricular cavity. Post-necrotic scarring was much less marked in Case 2 but here patchy scarring from embolic obstruction of small coronary vessels was also found. In the second case the endocardial fibrosis was more extensive and the endothelium replaced by widespread organizing thrombus.

\section{ATIOLOGY}

The cause of endocardial fibrosis is unknown. The insidious onset of the disease which probably long precedes the appearance of symptoms has made clinical study fruitless. The clinical and pathological resemblance of the cases occurring in Africa or in Africans to those found elsewhere does not imply that the cause is necessarily identical. Discussion is mainly concerned with those cases occurring in Africa. Malnutrition, including vitamin deficiencies, infection or parasitic infestation, and abnormal tissue response of the endocardium must be considered.

Davies (1948) working in East Africa concluded that malnutrition was the most likely cause. This was also the opinion of Smith and Furth (1943). In all Davies' cases evidence of malnutrition was found elsewhere in the body. Describing the native diet, he remarks that although very poor in protein it contains ample amounts of the B complex vitamins. Malnutrition is, however, very common amongst East African natives. The cases of Smith and Furth were regarded as a form of beri-beri as their diets were deficient in the B vitamins. The case of Toreson (1944) is described as being undernourished but no specific deficiencies are mentioned. In none of the other cases reported is malnutrition suggested. The West African soldiers described by Bedford and Konstam (1946) were probably having a fuller and better-balanced diet in the Army than they had ever had previously but it remains possible that the disease was established before they enlisted. Thiamin deficiency is the only dietary cause of cardiac disease that has yet been recognized. The cardiac effects of thiamin deficiency found clinically and experimentally must therefore be compared with endocardial fibrosis.

Although the cardiac form of beri-beri is seldom found in association with advanced peripheral neuritis, yet early neurological changes are common. The neurological changes sometimes found in endocardial fibrosis as in Case 2 bear no resemblance to peripheral neuritis. Clinical reports of cardiac beri-beri emphasize also that the condition of the circulation is very different from that described in endocardial fibrosis. There is a rapid bounding pulse with dilated vessels in the skin and increased pulse pressure, in fact, until the terminal stages, a failure of the high-output type. Recovery in the cardiac form of beri-beri following administration of thiamin is dramatic and almost invariable. Rapid improvement may be expected even in a moribund patient. Apart from true beri-beri, cardiac changes have bèn described in patients in America suffering from severe malnutrition with deficiency of the B vitamins. In a series of nine hundred such patients, Weiss and Wilkins (1936) found marked cardiovascular changes in a hundred and twenty, but in none of these did the condition resemble endocardial fibrosis. Pathologically, the lesion of beri- 
beri is a hydropic degeneration of the muscle fibres: myocardial necrosis and fibrosis are not found and there is no change in the endocardium.

Experimental thiamin defieiency must be severe and prolonged for myocardial changes to appear. Cardiac failure has been brought about in animals fed on deficient diets with recovery on the administration of thiamin. A focal necrosis of the myocardium was produced which appeared to be reversible. Fibrotic lesions have been described only once and they were diffusely distributed throughout the myocardium. In chastek paralysis, a disease of foxes believed to be due to a deficiency of thiamin, there is occasionally extensive myocardial necrosis and fibrosis (Evans et al., 1942).

Comparison with beri-beri and experimental thiamin deficiency gives no grounds for believing that endocardial fibrosis is due to deficiency of the B vitamins. The diet of the African is low in protein and high in carbohydrate. The relationship of such a diet to fatty degeneration and fibrosis of the liver is known but no cardiac changes have been reported in man or in experimental animals with hepatic disease of dietary cause. The occurrence of endocardial fibrosis in two well-nourished Europeans provides further evidence against the disease being due to dietary deficiency.

Various lesions in the myocardium and endocardium have been attributed to syphilis (Brooks, 1913; Morris, 1937). As well as gummata, patchy necrosis and cellular infiltration of the myocardium, and endocardial thickening have been thought syphilitic. Warthin (1925) described a series of eight cases in which extensive syphilitic lesions were present throughout the body where a diffuse inflammation with patchy fibrosis of the myocardium were found. Spirochætes were demonstrated in these lesions by special methods. Other pathologists have failed to confirm this, but Magill (1935) describes five cases of cardiac failure with histories - of syphilis and positive serological reactions in which scattered round cell infiltrations and scarring of the myocardium were present. It is unwise, however, to diagnose syphilitic myocarditis when signs of syphilis are lacking elsewhere and when the cardiac lesions are not gummatous. No cases of endocardial fibrosis have been definitely attributed to syphilis, but in several of Davies' (1948) cases a positive Wassermann reaction was found. This could be attributed to yaws, but evidence of syphilis elsewhere was occasionally found. The patient described by Edge (1946) was undergoing antisyphilitic treatment when the illness began. In Case 2 a positive serology was found which later became negative; there was, however, no history and no clinical or pathological evidence of syphilis. The absence of syphilitic lesions elsewhere in the great majority of reported cases, the rarity of positive complement fixation tests, and the pathology of the lesion oppose a syphilitic ætiology.

The possibility of cardiac lesions being caused by .African trypanosomiasis must be examined as there is no doubt that in the acate form of American trypanosomiasis or Chagas' disease the myocardium is involved as trypanosomes may be demonstrated inside muscle fibres. Chagas' disease has also a chronic form, in which the diagnosis is established by indirect means, which appears common in endemic areas. A form of myocardial fibrosis with cardiac failure is common in South America and a positive complement fixation test for $T$. Cruzi is found in such cases. The occurrence of myocarditis in the acute form of the disease and the recognition of a chronic myocarditis in the endemic regions has led to the identification of chronic myocarditis in South America with Chagas' disease. The circumstantial evidence for this is strong and a recent review of seventy-three cases of the chronic myocarditis of Chagas' disease (Ponde, 1948) describes a positive complement fixation test in every case and a positive zenodiagnostic test in thirteen of them, and in one out of four necropsies the trypanosome was demonstrated in the myocardium. Disorders of rhythm are very frequent in this type of chronic myocarditis (Chagas, 1928; Ponde, 1948). In this it differs clinically from endocardial fibrosis. Pathologically, there is patchy degeneration of myocardium, infiltration with inflammatory cells, and fibrosis (Johnson, 1943; Chagas, 1928; Ponde, 1948). The changes differ from those of endocardial fibrosis in being distributed throughout the entire thickness of the myocardium and there is no endocardial thickening or mural thrombosis. Comparison with the chronic myocarditis attributed to South 
American trypanosomiasis gives no grounds therefore for suspecting infection with this type of organism.

Trichina spiralis is recognized as causing a myocarditis that may prove fatal in the acute stages of trichiniasis (Zoller, 1927). There is necrosis of muscle fibres with eosinophilic infiltration and the larvæ may be found in the heart. There is no evidence that chronic heart disease follows such an invasion and in any case it is likely that the larvae would be demonstrable in the heart or elsewhere.

Diphtheritic myocarditis occasionally leads to a patchy fibrosis in the myocardium, and it has been suggested that this could lead to cardiac failure in later years. A history of severe diphtheria has not been found in cases of endocardial fibrosis and it is unlikely that such an illness could pass unnoticed. Furthermore the lesion in diphtheritic myocarditis is widespread and the endocardium is"not involved.

Cases of scleroderma have been described in which myocardial fibrosis has developed with intractable heart failure (Weiss et al., 1943). The clinical course and electrocardiographic changes resembled those of endocardial fibrosis but severe scleroderma was present for a long period before cardiac symptoms appeared. The heart in such cases showed a fibrotic change throughout the whole myocardium and the endocardium was not particularly affected. Scleroderma affecting the skin or the other viscera has not been described in cases of endocardial fibrosis. A resemblance of the lesions to those of scleroderma and certain cases of disseminated lupus erythematosus must, however, raise the possibility of endocardial fibrosis falling into the ill-defined category of the collagen diseases.

The frequency of eosinophilia may suggest that the nature of the disease lies in some allergic or hypersensitivity reaction. This was submitted by Mumme (1940) in discussing his case where endocardial fibrosis was found in association with intimal changes in many vessels throughout the body resembling those of thromboangiitis obliterans. There is no clinical or pathological evidence to support such a suggestion and in none of the experiments conducted with artificially induced hypersensitivity have endocardial lesions of this type been produced.

The relatively high incidence of endocardial fibrosis in Africa and the susceptibility of wellnourished Europeans favour an infectious cause in the African cases, and it is possible that sporadic cases encountered elsewhere are caused by some entirely different agent. The frequency of eosinophilia suggests an unrecognized parasitic infection or possibly some allergic response of the body. The lesion itself does not appear inflammatory but could be the result of the healing of an inflammatory process as in the fibrous scarring that follows rheumatic valvulitis. Early diagnosis of the condition must remain difficult except possibly in Africa but it is only from study of cases in their early stages that a causative organism is likely to be identified, and it is only in the early stages that therapeutic measures are likely to be of any use.

\section{SUMMARY}

Attention is drawn to endocardial fibrosis as a cause of chronic congestive failure frequently complicated by multiple arterial emboli.

The clinical and pathological features of this condition are described.

The greater frequency of this disease in Africa than in Europe or America is stressed and two fatal cases described occurring in Europeans who had been living in West Africa.

The cause of endocardial fibrosis is discussed and vitamin B deficiency rejected. No other nutritional cause of cardiac disease is recognized.

Possible infections are discussed and it is considered possible that an unrecognized parasitic, bacterial, or viral agent may cause the disease.

I wish to thank Dr. Evan Jones for his permission to publish Case 1 and for allowing me access to his records at St. Thomas' Hospital, and Prof. M. L. Rosenheim for permission to publish Case 2. My thanks are also due to Dr. R. A. B. Drury for his great assistance with the pathology and to Dr. D. Evan Bedford and Dr. J. D. N. Nabarro for their advice and help, and to Mr. A. Bligh who prepared the photographs. 


\section{REFERENCES}

Bedford, D. Evan, and Konstam, G. L. S. (1946). Brit. Heart J., 8, 236.

Boikan, W. S. (1931). Virchow's Arch. path. Anat., 282, 46.

Brooks, H. (1913). Amer. J. med. Sci., 146, 513.

Chagas, Ev. (1928). Arch. Mal Coeur, 21, 641.

Davies, J. N. P. (1948). M.D. thesis, Bristol.

Edge, J. R. (1946). Lancet, 2, 675.

Egger, P. (1944). Schweiz. Z. Path. Bakt., 7, 237.

Evans, C. A., Carlson, W..E., and Green, R. G. (1942). Amer. J. Path., 18, 79.

Flynn, J. E., Mann, F. D. (1946). Amer. Heart J., 31, 757.

Gallavardin, L., and Gravier, L. (1929). Arch. Mal. Coeur, 22, 379.

Johnson, C. M. (1943). Med. Clin. North America, 822.

Josserand, E., and Gallavardin, L. (1901). Arch. Gen. Med., 188, 513.

Kugel, M. A., and Stoloff, E. G. (1933). Amer. J. Dis. Child., 45, 828.

Levy, R. L., and Rousselot, L. M. (1933). Amer. Heart J., 9, 178.

Loeffler, W. (1936). Schweiz. med. Wchnschr., 17, 817.

Magill, T. P. (1935). Bull. Johns Hopkins Hosp., 57, 22.

Mahon, C. S. (1936). Amer. Heart J., 12, 608.

Morris, J. C. (1937). J. Amer. med Assoc., 108, 169.

Mumme, C. (1940). Z. klin. Med., 138, 22.

Ponde, A. (1948). Prensa Med. Argent., 35, (i), 1075.

Reisinger, J. A., and Blumenthal, B. (1941). Amer. Heart J., 22, 811.

Roque, G., and Levy, L. (1914). Arch. Mal. Coeur, 7, 10.

Smith, F. M., and Stephens, R. L. (1938). Trans. Ass. Amer. Phys., 53, 120.

Smith, J. J., and Furth, J. (1943). Arch. intern. Med., 71, 602.

Toreson, W. E. (1944). Ibid., 73, 375.

Ware, E. R., and Chapman, B. M. (1947). Amer. Heart J., 33, 530.

Warthin, A. S. (1925). Ibid., 1, 1.

Weiss, S., and Wilkins, R. W. (1936). Ann. intern. Med., 11, 104.

, Stead, E. A., Warren, J. V., and Bailey, O. T. (1943). Ibid., 71, 749.

Zoller, H. (1927). Virchows Arch. páth. Anat., 2665, 430. 